\title{
Macroautophagy deficiency mediates age-dependent neurodegeneration through a phospho-tau pathway
}

Keiichi Inoue ${ }^{1}$, Joanne Rispoli, Hanoch Kaphzan², Eric Klann², Emily I Chen ${ }^{3}$, Jongpil Kim ${ }^{1}$, Masaaki Komatsu ${ }^{4}$ and Asa Abeliovich ${ }^{1 *}$

\begin{abstract}
Background: Macroautophagy is an evolutionarily conserved mechanism for bulk intracellular degradation of proteins and organelles. Pathological studies have implicated macroautophagy defects in human neurodegenerative disorders of aging including Alzheimer's disease and tauopathies. Neuronal deficiency of macroautophagy throughout mouse embryonic development results in neurodevelopmental defects and early postnatal mortality. However, the role of macroautophagy in mature CNS neurons, and the relationship with human disease neuropathology, remains unclear. Here we describe mice deficient in an essential macroautophagy component, Atg7, specifically within postnatal CNS neurons.

Results: Postnatal forebrain-specific Atg7 conditional knockout (cKO) mice displayed age-dependent neurodegeneration and ubiquitin- and p62-positive inclusions. Phosphorylated tau was significantly accumulated in Atg7 CKO brains, but neurofibrillary tangles that typify end-stage human tauopathy were not apparent. A major tau kinase, glycogen synthase kinase $3 \beta$ (GSK3 $\beta$ ), was also accumulated in Atg7 cKO brains. Chronic pharmacological inhibition of tau phosphorylation, or genetic deletion of tau, significantly rescued Atg7-deficiency-mediated neurodegeneration, but did not suppress inclusion formation.

Conclusions: These data elucidate a role for macroautophagy in the long-term survival and physiological function of adult CNS neurons. Neurodegeneration in the context of macroautophagy deficiency is mediated through a phospho-tau pathway.
\end{abstract}

\section{Background}

The primary etiologies of neurodegenerative disorders, including Alzheimer's disease (AD), frontotemporal dementia (FTD) and Parkinson's disease (PD), remain largely unknown, but common pathological features suggest a role for altered protein degradation. For instance, proteinaceous intracellular inclusions composed in part of aggregated $\alpha$-synuclein protein, termed Lewy bodies, typify PD brain pathology, whereas neurofibrillary tangles (NFT) and Pick bodies containing phosphorylated tau protein are commonly found in the context of taupathies such as AD and FTD. Rare, inherited familial forms of neurodegenerative diseases [1] are caused by

\footnotetext{
* Correspondence: aa900@columbia.edu

'Departments of Pathology and Neurology, Taub Institute, Columbia University Medical Center, 650 W. 168th St., New York, NY 10032, USA Full list of author information is available at the end of the article
}

mutations in genes encoding these accumulated proteins, such as $\alpha$-synuclein $[2,3]$ in PD and tau in FTD, but the vast majority of patients do not harbor known mutations. Thus, it has been hypothesized that in these 'sporadic' cases, pathological inclusions may reflect broadly defective protein degradation through mechanisms such as the ubiquitin-proteasome system (UPS) [4] and macroautophagy $[5,6]$. The latter is of particular interest because of its apparent role in the degradation of protein aggregates and inclusions [7].

Macroautophagy is a pathway of bulk cytoplasmic protein and organelle degradation characterized by doublemembrane vesicles that engulf cargo and target it to lysosomes for degradation [8]. The pathway is typically induced in the context of starvation or other stressors. Defects in the macroautophagy process may theoretically occur at a variety of steps, from the initial formation of a 
pre-autophagosome limiting membrane, to the ultimate fusion of mature autophagosomes with the lysosomal compartment [9]. Macroautophagy defects have been well described on pathological analyses of brain sections from patients with a variety of neurodegenerative disorders, including AD, PD and FTD [5,10]. Furthermore, inherited genetic forms of neurodegeneration are associated with mutations in the macroautophagy-lysosomal pathway $[11,12]$. Finally, as macroautophagy dysfunction is a well-documented feature of aging, it has been implicated in the age-dependent nature of the major neurodegenerative disorders $[5,9,10]$.

Genetically altered mice that are deficient in essential macroautophagy pathway components, Atg5 or Atg7, throughout neural development, display reduced neuronal survival and harbor ubiquitin-positive inclusions in the cell soma [13-16]. But surprisingly, prevention of inclusion formation in the context of Atg7-deficiency by a second genetic ablation of p62, which encodes an ubiquitin-binding protein associated with autophagosomes, does not suppress neurodegeneration, arguing against a toxic role for inclusions [17]. Thus, the mechanism of neuronal loss with macroautophagy deficiency, and how this relates to neurodegeneration, remains unclear.

Here we generated conditional Atg7-deficient mice specifically within mature CNS neurons. Atg7-deficient neurons were defective in the initiation of macroautophagy, and displayed a progressive degeneration with prominent inclusions that harbor ubiquitin, p62, phosphorylated tau and GSK3 3 . The mutant mice exhibited behavioral deficits consistent with the pathological changes. Furthermore, pharmacological or genetic suppression of tau phosphorylation effectively inhibited neurodegeneration in the context of Atg7-deficiency in vivo.

\section{Results}

Slowly progressive degeneration of postnatal

Atg7-deficient hippocampal CA1 neurons

Genetically altered mice that are deficient in an essential component of the macroautophagy machinery, Atg7 [18], specifically within mature forebrain neurons, were generated using a Cre-loxP strategy [19]. Briefly, we interbred mice that express bacterial Cre recombinase (CRE) under the control of the CamKII $\alpha$ gene regulatory sequences (CamK-Cre) [20] with Atg $7^{\text {flox/flox }}$ mice [19]. CRE expression was limited to CA1 field pyramidal neurons of the hippocampus and glutamatergic neurons within the cerebral cortex [20], leading to ATG7 loss and prominent macroautophagy defects including the accumulations of LC3, GABARAP, GABARAPL1, and p62 in forebrain specific Atg7 conditional knockout (CamK-Atg7 cKO) mice (Figure 1a,b). Quantification of CA1 pyramidal neuron number revealed a significant reduction of approximately $25 \%$ in CamK-Atg7 cKO mice at 1-year of age, while 3-month-old cKO mice maintained a normal complement of CA1 neurons (Figure 1c). Consistent with the neurodegenerative process, hippocampal CA1 neurons of 8-month-old CamK-Atg7 cKO mice stained positively for cleaved caspase-3 (Figure 1d). In contrast, neither neuronal loss nor caspase-3 positive signal was observed in the cerebral cortex of 1-year-old CamK-Atg7 cKO mice.

Furthermore, numerous ubiquitin-positive inclusions were apparent in essentially all Atg7-deficient CA1 cell bodies from 2-month of age, whereas these were never seen in the control CamK-Atg7 cWT mice (Figure 1e). These inclusions were stained positive for p62 [17,21], which is a component of the macroautophagy machinery pathway (Additional file 1), and further confirmed the macroautophagy defect in forebrain neurons. In contrast, such inclusions were absent from the CA3 neurons (data not shown). Further analysis by electron microscopy revealed that these inclusions were composed of both filamentous and vesicular elements (Figure 1f).

We further compared CamK-Atg7 cKO neurodegeneration with the effect of Atg7 deficiency in a second population of mature CNS neurons, midbrain dopamine (DA) neurons. To this end, we generated animals that express CRE under the control of the dopamine transporter (Dat) gene regulatory elements, and are homozygous for the floxed Atg7 allele (Dat ${ }^{C r e /+} A \operatorname{tg} 7^{\text {flox/flox }}$; DatAtg7 cKO mice rather than CamK-Atg7 cKO mice). Dat-Atg7 cKO mice displayed a very similar pathological progression to CamK-Atg7 cKO mice with cytoplasmic ubiquitin- and p62-positive inclusions, albeit the process is selective for midbrain DA neurons as expected (Additional file 2c,d). Neurodegeneration progresses appeared more rapid in the Dat-Atg7 cKO mouse model than the CamK-Atg7 cKO mouse model $(25 \%$ midbrain DA neuron lost at 2-months of age and 38\% lost at 4-month; Additional file 2a,b).

\section{Atg7 deficiency in mouse postnatal forebrain neurons results in physiological and behavioral deficits}

We further examined the physiological and behavioral consequences of Atg7-deficiency within forebrain neurons. Extracellular recording of field potentials were performed at Schaffer collateral synapses in area CA1 of acutely prepared hippocampal slices from 3-month-old male CamK-Atg7 cKO mice and control CamK-Atg7 cWT littermates. CamK-Atg7 cKO mice showed normal input/output amplitudes in response to single stimuli (Figure 2a), as well as intact paired-pulse facilitation (PPF) at a variety of interpulse intervals (Figure 2b). These findings suggest that there are no gross differences in synaptic organization or baseline synaptic transmission in the cKO mice at this age. In contrast, early long-term potentiation (E-LTP) induced by a single 

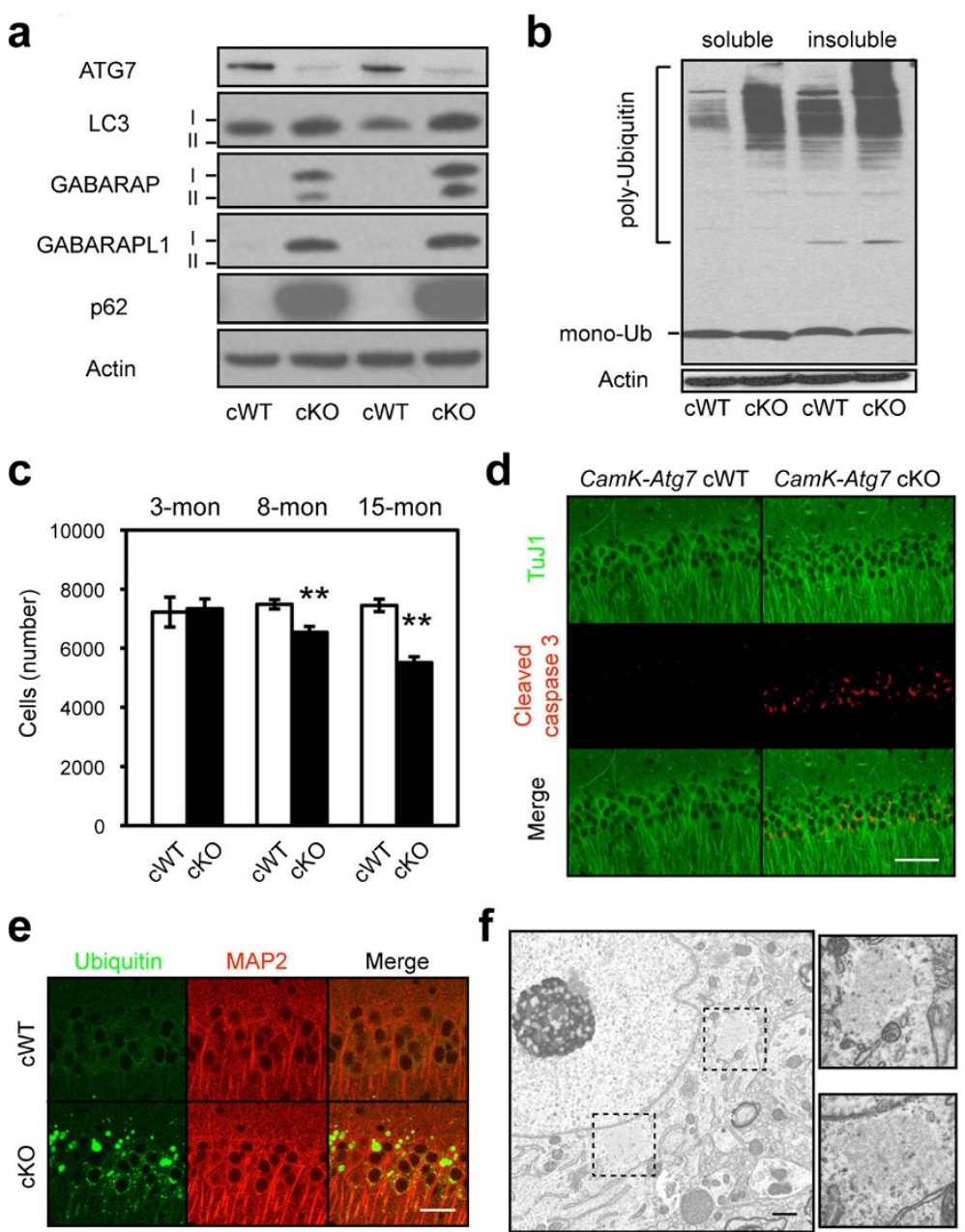

Figure 1 Age-dependent neurodegeneration in forebrain-specific Atg7-deficient mice. (a-b) Impaired macroautophagy in CamK-Atg7 cKO mouse forebrain tissues including hippocampus and cortex. a, ATG7 protein was significantly reduced in CamK-Atg7 cKO brains. Consistent with ATG7 change, mammalian Atg8 homologues (LC3, GABARAP and GABARAPL1) and macroautophagy substrate p62 were accumulated in CamK-Atg7 CKO brains. b. Poly-ubiquitinated proteins were accumulated in both $0.5 \%$ TritonX-100-soluble and insoluble fractions of CamK-Atg7 cKO forebrain. These results indicate that macroautophagy is impaired in the forebrains of CamK-Atg7 CKO mice. (c-d) Slow progressive loss of hippocampal CA1 pyramidal neurons in CamK-Atg7 CKO mice. c, Quantification of CA1 pyramidal neuron number. White bars, CamK-Atg7 cWT. Black bars, CamK-Atg7 CKO. $\mathrm{n}=3$ - 4 for each group. ${ }^{*}, \mathrm{P}<0.01$. d, Pyramidal neurons in the CA1 region of 8-month-old CamK-Atg7 cKO mice were cleaved caspase-3-positive. Bar, $40 \mu \mathrm{m}$. (e) Cytoplasmic inclusions in 6-month-old CamK-Atg7 cKO mice. Ubiquitin-positive (green) inclusions were present in MAP2-positive (red) hippocampal CA1 neurons of CamK-Atg7 cKO mice, but were never seen in control CamK-Atg7 cWT mice. Ubiquitin-positive inclusions were also positive for p62 (Additional file 1), as previously. Bar, $10 \mu \mathrm{m}$. (f) Electron microscopic analyses of cytoplasmic inclusions. The dashed squares outline two inclusions in the cytoplasm on neurons of Atg7 cKO mice. At higher magnification, these inclusions display fibrillar and vesicular components and lack an outer membrane. Inclusions were never observed in control cWT mice. Bar, $500 \mathrm{~nm}$.

high-frequency tetanic stimulation - a long-lasting protein synthesis-independent form of synaptic potentiation - was impaired in CamK-Atg7 cKO slices (Figure 2c). In contrast, we note that long-term depression was intact in the cKO mice (data not shown). The relatively selective physiological impairment is unlikely to be secondary to the limited cell loss.

Next, we assessed forebrain-dependent fear conditioning in CamK-Atg7 cKO mice and CamK-Atg7 cWT mice. CamK-Atg7 cKO mice did not show any increase in the ratio of freezing at their basal level. However, CamK-Atg7 cKO mice showed a significant impairment in contextual fear conditioning relative to control CamK-Atg7 cWT animals (Figure 2d). Furthermore, the cKO mice showed significant reduced freezing ratio in cued fear conditioning, whereas the basal freezing ('Pre-Test') was not changed (Figure 2e). Taken together, these data demonstrate forebrain physiological dysfunction, consistent with the selective forebrain pathology of CamK-Atg7 cKO mice. 

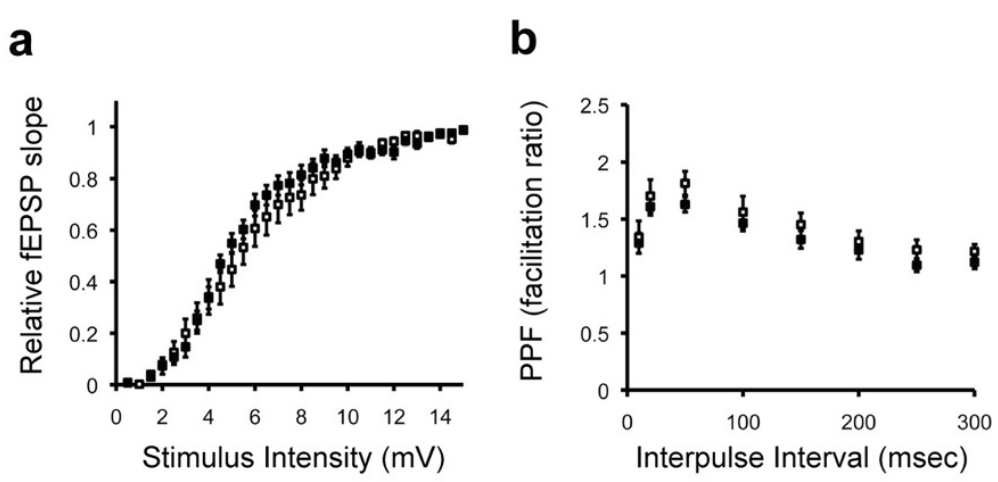

C
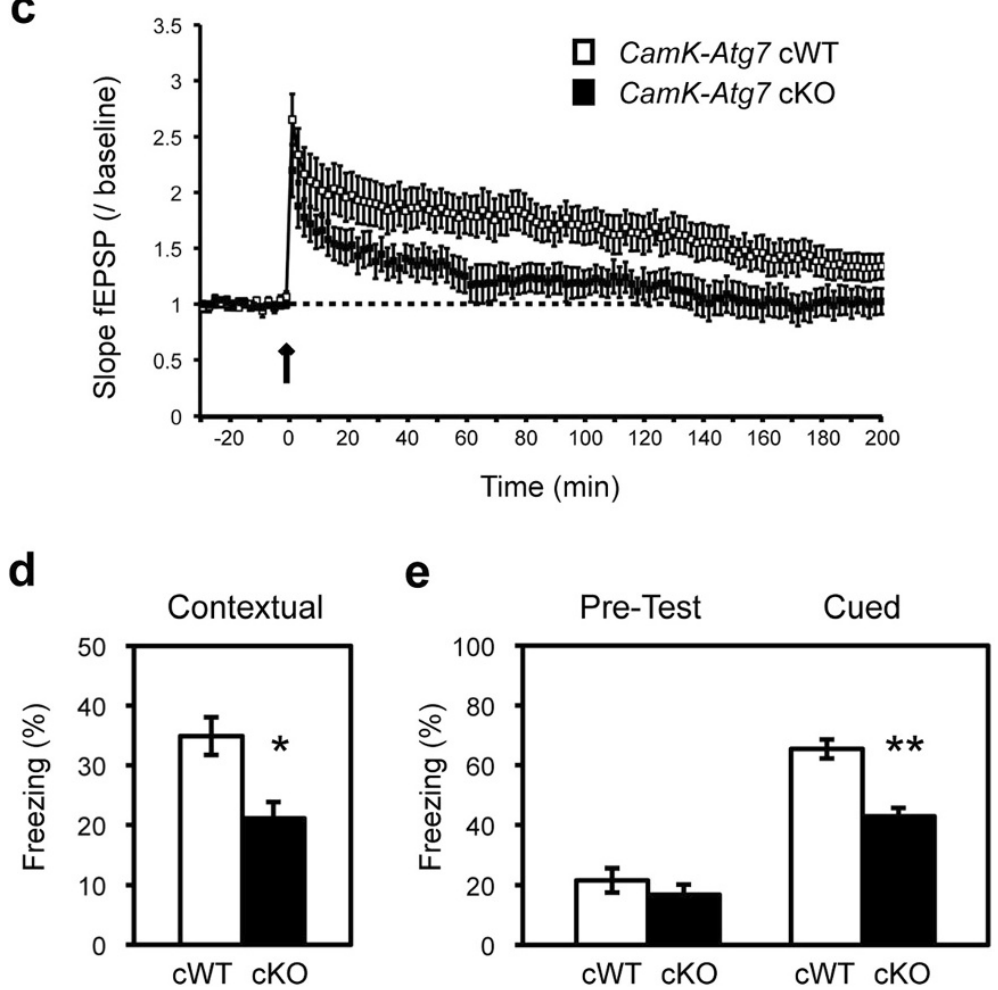

Figure 2 Physiological and behavioral alterations in forebrain-specific Atg7-deficient mice. (a-c) Forebrain-specific Atg7 CKO mice display normal basal synaptic transmission but impaired LTP of the Schaffer collateral tract. Extracellular recording of field potentials was performed at area CA1 of acutely prepared hippocampal slices from 3-month-old male CamK-Atg7 cKO mice and CamK-Atg7 cWT littermates. a, Plots of fEPSP slope (normalized to maximal) versus stimulus intensity. There was no significant difference in baseline synaptic transmission between CamK-Atg7 cKO mice and CamK-Atg7 cWT littermates. $n=12$ slices from 3 mice per genotype. b. Paired-pulse facilitation in CamK-Atg7 cKO mice. The percent facilitation, determined by the ratio of the second fEPSP initial slope to the first fEPSP initial slope, is shown at interpulse intervals from 10 to 300 ms. $n=12$ slices from 3 mice per genotype. c, Impaired LTP in CamK-Atg7 cKO mice. Stable baseline responses were recorded prior to HFS ( $100 \mathrm{~Hz}$ HFS for $1 \mathrm{~s}$ ) as indicated by arrow. One train of $100 \mathrm{~Hz}$ HFS elicited E-LTP in CamK-Atg7 CKO mice that was decreased compared with that evoked in CamK-Atg7 CWT mice. Open squares, CamK-Atg7 CWT; Filled squares, CamK-Atg7 CKO. $\mathrm{n}=12$ slices from 3 mice per genotype. $p<0.01$ by repeated measures ANOVA. (d-e) Impaired fear memory of forebrain-specific Atg7 CKO mice. d, CamK-Atg7 cKO mice showed significant impairment in contextual fear memory $24 \mathrm{~h}$ after the training. e, CamK-Atg7 cKO mice had impaired cued fear memory in the third day. Freezing level before the cue (tone) was not altered in CamK-Atg7 CKO mice relative to CamK-Atg7 CWT littermates ('Pre-Test'). White bars, CamK-Atg7 cWT ( $n=10)$; Black bars, CamK-Atg7 cKO $(n=8) .{ }^{*}, P<0.05 .{ }^{* *}, P<0.01$.

Phospho-tau-positive inclusions in Atg7-deficient neurons We investigated whether neurodegeneration caused by Atg7-deficiency is associated with typical pathological hallmarks of human neurodegenerative syndromes. Macroautophagy has previously been implicated in the clearance of various proteins implicated in human neurodegenerative syndromes including Alzheimer precursor protein (APP), $\alpha$-synuclein, TDP-43, tau, and huntingtin [22-29]. However, direct in vivo evidence of an essential role for macroautophagy in the degradation of these 
proteins in forebrain is lacking. No accumulation of APP (or the APP-derived peptide fragmant $\beta$-amyloid), $\alpha$-synuclein, or TDP-43 was detected in CamK-Atg7 cKO mouse brain (Additional file 3a, b). However, cytoplasmic inclusions in Atg7-deficient CA1 pyramidal neurons and cerebral cortex neurons were prominently stained with multiple well-characterized antibodies to phospho-tau including AT8 (epitope at Ser202/Thr205), AT100 (epitope at Ser212/Thr214), and TG3 (epitope at Thr231/Ser235) [30,31] (Figure 3a-c). Similarly, electron microscopic analysis confirmed TG3-positive staining in the cytoplasmic inclusions of Atg7-deficient neurons (Figure 3d). We note that the inclusions were not stained with other antibodies for mature phospho-tau positive inclusions in human pathology, AT270 (epitope at Ser181) and PHF1 (epitope at Ser396/Ser404). Furthermore, the cytoplasmic inclusions did not stain with Thioflavin $\mathrm{S}$, which marks mature NFTs in human tauopathies (Additional file 3c).

Quantitative Western blotting of forebrain extracts revealed that phospho-tau protein epitopes were broadly increased in forebrain tissues from CamK-Atg7 cKO mice, whereas total tau protein appeared unaltered (Figure 3e). Several epitopes, including AT8, AT100, and TG3, were increased in both $0.5 \%$ TritinX-100-soluble and insoluble brain extracts (relative to CamK-Atg7 cWT controls; Figure 3e), whereas AT180 accumulated only in insoluble extracts, and accumulation was not altered for AT270 and PHF1 (Figure 3e). The phosphotau epitope staining pattern appeared very similar in midbrain DA neurons of Dat-Atg7 cKO mice (Additional file 2e, Figure 4e). A similar phospho-tau pattern has previously been suggested to represent an early 'pre-tangle' state [32]; this may reflect an early stage of non-fibrillar tau aggregation prior to its assembly into paired helical filaments (PHF). Taken together, these data implicate phospho-tau accumulation in Atg7deficiency-mediated neurodegeneration. However, the phospho-tau aggregates in the context of Atg7-deficient neurons do not replicate aspects of mature human tauopathy pathology.

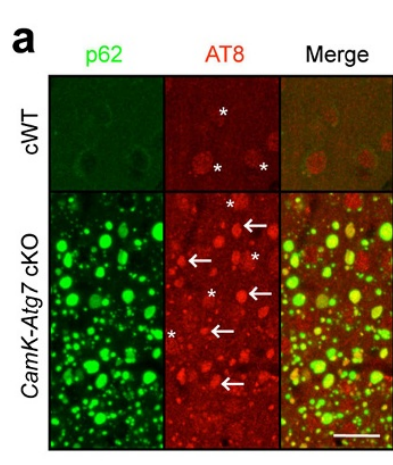

d

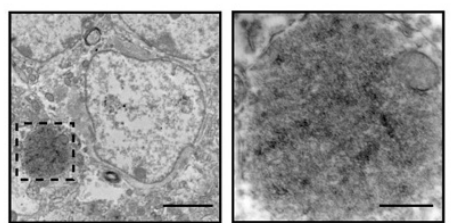

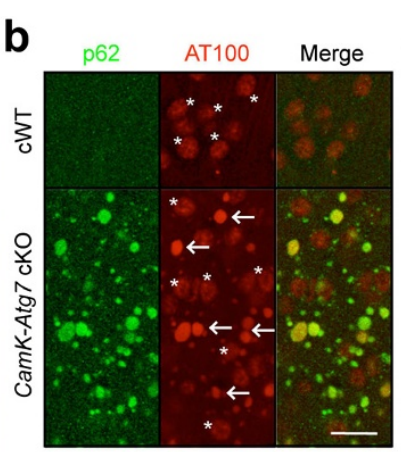

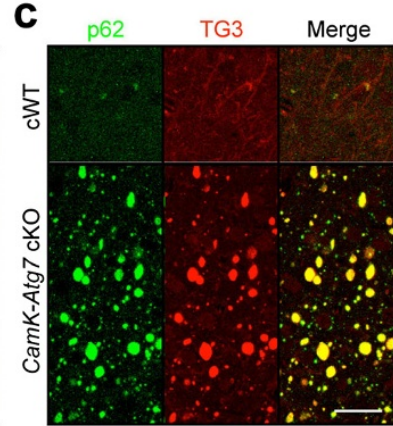

e

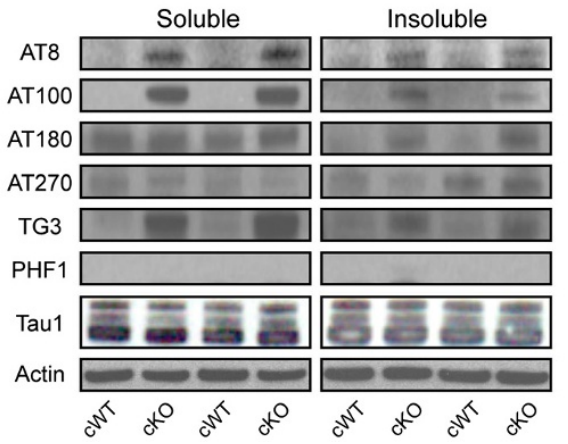

Figure 3 Phospho-tau-positive inclusions in conditional Atg7-deficient mice. (a-c) Phospho-tau-positive inclusions in cortical neurons of CamK-Atg7 CKO mice. a, AT8, an antibody against phospho-tau at Ser202/Thr205 residues (red, arrows), stained p62-positive inclusions (green) in

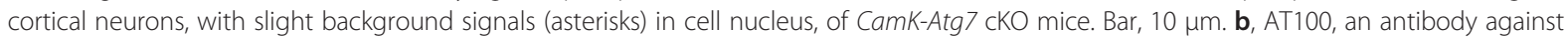
phospho-tau at Ser212/Thr214 residues (red, arrows), stained p62-positive inclusions (green) in cortical neurons, with slight background signals (asterisks) in cell nucleus, of CamK-Atg7 CKO mice. Bar, $10 \mu \mathrm{m}$. c, TG3, an antibody against phospho-tau at Thr231/Ser235 residues (red, arrows), stained p62-positive inclusions (green) in cortical neurons of CamK-Atg7 CKO mice. Bar, $10 \mu \mathrm{m}$. (d) Immunoelectron microscopic analysis of phospho-tau-positive inclusion in CamK-Atg7 CKO mice. Immunoelectron microscopic analysis of inclusions using the phospho-tau-specific antibody TG3 and horseradish peroxidase staining (dark speckles; contrast to Figure. 1f). At right is a high magnification image of the inset (dashed square in left). Bars, $2 \mu \mathrm{m}$ (left) and $500 \mathrm{~nm}$ (right). (e) Phospho-tau levels are elevated in forebrain extracts of CamK-Atg7 cKO mouse. Western blotting reveals that AT8-, AT100- or TG3-positive phospho-tau is significantly increased in both $0.5 \%$ Triton X-100-soluble and -insoluble fractions of CamK-Atg7 CKO brain tissue extracts. AT270- or PHF1-positive phospho-tau and total tau [Tau1] were not changed. $n=5$. Two independent samples are presented for each genotype, as labelled at bottom. 

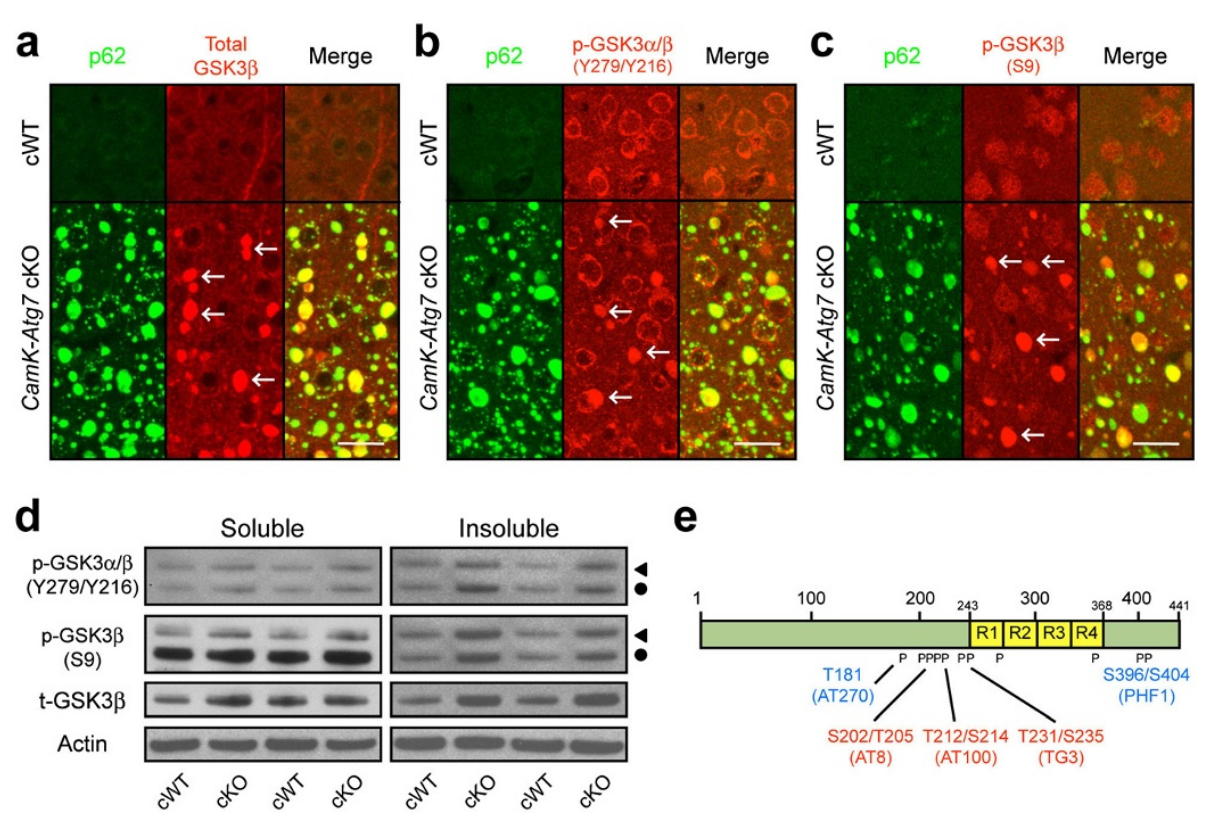

Figure 4 GSK3 $\beta$-positive inclusions in conditional Atg7-deficient mice. (a-c) GSK3ß-positive inclusions in cortical neurons of CamK-Atg7 cKO mice. a, An antibody recognizing total GSK3 3 (red, arrows), stained p62-positive inclusions (green) in cortical neurons of CamK-Atg7 cKO mice. Bar, $10 \mu \mathrm{m}$. b. Antibodies recognizing phosphorylated, activated form of GSK3 $\beta$ (Tyr279/Tyr216; in red, arrows) stained p62-positive (green) inclusions in cortical neurons of CamK-Atg7 CKO mice. Bar, $10 \mu \mathrm{m}$. c, An antibody recognizing phosphorylated inactivated forms of GSK3 $\beta$ at Ser9 residues (red, arrows), stained p62-positive inclusions (green) in cortical neurons of CamK-Atg7 cKO mice. Bar, $10 \mu \mathrm{m}$. (d) GSK3 $\beta$ levels are elevated in the forebrain extracts of CamK-Atg7 CKO mouse. Western blotting reveals that phosphorylated forms of GSK3 $\beta$ (both activated Tyr216 residue and inactivated Ser9 residue) as well as total GSK3 $\beta$ were significantly increased in CamK-Atg7 cKO brain tissue extracts. Triangle, GSK3a. Circle, GSK3 $3 . n=5$ per group. (e) Summary of phosphorylation and antibody recognition sites of human tau protein. The phosphorylated sites (Ser202/Thr205 [AT8], Thr212/Ser214 [AT100], and Thr231/Ser235 [TG3] residues) in Atg7-deficient mice are shown in red. Non-phosphorylated sites are shown in blue. Phosphorylation sites are numbered according to the human tau protein by convention; the homologous corresponding phosphorylation sites in the mouse tau protein are each positioned 11 amino acids towards the amino terminus.

\section{GSK3 $\beta$ staining at phospho-tau inclusions in Atg7-deficient neurons}

Given the accumulation of phosphorylated - but not total - tau in Atg7-deficient neurons (Figure 4e), we hypothesized that a kinase that is known to phosphorylate tau, such as GSK3 $\beta$, may be altered. Immunostaining of cortical neurons revealed dramatic re-localization of GSK3 $\beta$, including both active (epitope at Tyr216) and inactive (epitope at Ser9) phosphorylated forms, to phospho-tau-positive and ubiquitin/p62-positive inclusions in Atg7-deficient neurons (Figure 4a-c). Western blot analysis confirmed that total and phosphorylated forms of GSK3 $\alpha / \beta$ were increased in forebrain tissue extracts from CamK-Atg7 cKO mice, compared to CamK-Atg7 cWT mice (Figure 4d). Another kinase implicated in phosphorylation of tau, CDK5, did not appear to be re-localized to the inclusions in Atg7deficient neurons [33] (Additional file 4d). Inclusions in Atg7-deficient neurons stained positively for a second microtubule-associated GSK3 $\beta$ substrate, phosphoCRMP2 [34] (Additional file 4a,b). In contrast, $\beta$-Catenin, a well-described GSK3 $\beta$ substrate in the context of Wnt signaling pathway, did not appear altered in staining in
Atg7-deficient neurons (Additional file 4c). Thus, accumulated GSK3 $\beta$ in the context of Atg7-deficiency appears to display substrate specificity, perhaps related to subcellular re-localization at inclusions.

\section{Pharmacological or genetic inhibition of phospho-tau accumulation can rescue neuronal cell death in vivo}

To examine the causality between phospho-tau and neurodegeneration in the context of Atg7-deficiency, we sought to determine whether neurons deficient in Atg7 could be effectively protected in vivo through the modulation of phospho-tau production. We focused these 'rescue' studies on Dat-Atg7 cKO mice (rather than CamK-Atg7 cKO mice) because the neurodegeneration progresses more rapidly in Dat-Atg7 cKO mouse model than CamK-Atg7 cKO mouse model, as noted above, and the degenerative and pathological processes are restricted to a single cell type in the Dat-Atg7 cKO mice (midbrain DA neurons; Additional file 2a,b). Dat-Atg7 cKO mice also displayed a very similar pathological progression to CamK-Atg7 cKO mice with cytoplasmic ubiquitin- and p62-positive inclusions (Additional file 2c,d) that further stain for phospho-tau and GSK3 $\beta$ (Additional file 2e,f). 
Thus, analysis of pathology in Dat-Atg7 cKO mice affords a more facile and accurate quantification of the cell autonomous impact of macroautophagy on the loss of mature CNS neurons.

To investigate the role of phospho-tau accumulation in Atg7-deficiency-induced neurodegeneration, Dat-Atg7 cKO or Dat-Atg7 cWT mice were treated chronically with a potent GSK3 $\beta / C D K 5$ inhibitor, Alsterpaullone (5 $\mathrm{mg} / \mathrm{kg} / \mathrm{d}$, i.p.) for a period of 3 weeks starting at 5-week of age [35]. Alsterpaullone can inhibit the activities of GSK3 $\beta$, as well as several other tau kinases (CDK1/2/5, GSK $3 \alpha$, and, to lesser extent, ERK1/2 and PKA) to suppress tau phosphorylation (Additional file 5a) [36]. At the end of the treatment course (8-weeks of age), pathological examination of the mice revealed that Alsterpaullone treatment led to a significant increase in the survival of midbrain DA neurons in Dat-Atg7 cKO mice $(24.3 \%$ increased survival, $\mathrm{p}<0.01)$, whereas Alsterpaullone-treated control Dat-Atg7 cWT mice appeared unaltered (Figure $5 \mathrm{a}, \mathrm{b}$ ). In contrast, ubiquitinpositive inclusions were unchanged in size and number in Alsterpaullone-treated Dat-Atg7 cKO mice, whereas no inclusions were seen in Alsterpaullone-treated Dat-Atg7 cWT mice (Additional file $5 \mathrm{~b}, \mathrm{c}$ ). This is consistent with the previous report that the inclusion formation and neurodegeneration are independent in the context of macroautophagy deficiency [17]. These in vivo results are suggesting a protective effect by phospho-tau inhibition in the context of macroautophagy deficiency-induced neurodegeneration. As Alsterpaullone does display some inhibitory activity at kinases in addition to GSK3ß, such as CDK5 [36], we cannot exclude additional in vivo kinase targets. But we note that unlike GSK3 $\beta$, CDK5 did not appear modified or re-localized in Dat-Atg7 cKO neurons (Additional file 4d).

Next, we examined the effect of tau-deficiency [37] in Dat-Atg7 cKO mice. We generated Dat-Atg7/tau double cKO (Dat ${ }^{C r e /+} A \operatorname{tg} 7^{\text {flox/flox }}$ tau $\left.^{-/-}\right)$mice, and compared the loss of midbrain DA neuron in Dat-Atg7 single cKO $\left(\mathrm{Dat}^{\mathrm{Cre} /+} \mathrm{Atg}^{\text {flox/flox }} \mathrm{tau}^{+/+}\right.$or $\mathrm{Dat}^{\mathrm{Cre} /+} \mathrm{Atg}^{\text {flox/flox }} \mathrm{tau}^{+/-}$) and Dat-Atg7/tau double cKO mice. The loss of midbrain DA neurons in Dat-Atg7 cKO mice was significantly rescued in Dat-Atg7/tau double cKO mice at the age of 3-month (Figure 5c,d). Again, the formation of ubiquitin-positive inclusion was not changed in Dat-Atg7/tau double cKO mice (Additional file 5d,e). Consistent with the previous report that tau-deficiency alone led to no abnormality in the brain $[37,38]$, neither neurodegeneration nor ubiquitin/p62-positive inclusions was seen in the midbrain DA neurons of tau KO mice (Figure 5c,d and Additional file 5d,e). Taken together, these approaches support a model whereby accumulation of phospho-tau contributes to neurodegeneration in the context of macroautophagy-deficiency, whereas the formation of ubiquitin/p62-positive inclusions is independent of phospho-tau signaling.

\section{Discussion}

Here we investigated mechanisms of neurodegeneration downstream of Atg7-deficiency, and describe the pathological accumulation of GSK $\beta$ and phospho-tau proteins. A striking feature of neuropathology in the context of Atg7-deficiency is the redistribution of GSK3 $\beta$ to inclusions. We note that both GSK3 $\beta$ and phospho-tau are reported to be found in inclusions in tauopathy patient brain [39-43]. However, it is important to emphasize that Atg7-deficiency does not appear to induce a full tauopathy pathology, as not all phospho-tau epitopes are observed (e.g., PHF1 antibody is negative, Figure 4e), and amyloid staining with Thioflavin $\mathrm{S}$, as well as electron microscopic analysis, do not support the presence of mature NFTs. A similar phospho-tau pattern has previously been suggested to represent an early 'pre-tangle' pathological state [32], thought to reflect non-fibrillar tau aggregation prior to assembly into PHFs. Such nonfibrillar hyperphosphorylated tau, rather than mature NFTs, may be the relevant toxic form in vivo in the context of neurodegeneration and behavioral impairment [44]. Hoozemans et al. reported phospho-tau-positive pre-tangles with accumulation of GSK3 $\beta$, ubiquitin and p62 in postmortem specimens of AD patients [45], reminiscent of pathology in Atg7-deficient neurons in vivo. Phospho-tau pathology as seen in Atg7-deficient animals may broadly relate to neuronal dysfunction in neurodegeneration, as macroautophagy deficiency and phospho-tau are commonly observed in a broad array of neurodegenerative disorders including $\mathrm{AD}, \mathrm{PD}$, tauopathy, huntington disease, amyotrophic lateral sclerosis, and Gaucher disease [6,46-49]. Although genetic mutations in ATG7 have not been described in human disease, mutations within other components of the macroautophagy-lysosomal pathway underlie tauopathies [50], consistent with our observations in the mouse model.

The in vivo pharmacological and genetic 'rescue' studies herein suggest a role for phospho-tau accumulation in neurodegeneration downstream of Atg7-deficiency. In contrast, prior attempts to rescue macroautophagydeficiency associated neurodegeneration by preventing the formation of aggregates, by generation of doubleknockout mice deficient in Atg7 as well as p62, were unsuccessful [17], suggesting that inclusion formation per se is insufficient for degeneration. It is interesting to note that nonetheless, p62 deletion does rescue the Atg7 deficiency-associated cell loss in hepatocytes [17], and thus degenerative pathways downstream of macroautophagy loss appear cell type-specific. Furthermore, within the CNS, various neuronal subtypes appear to be 

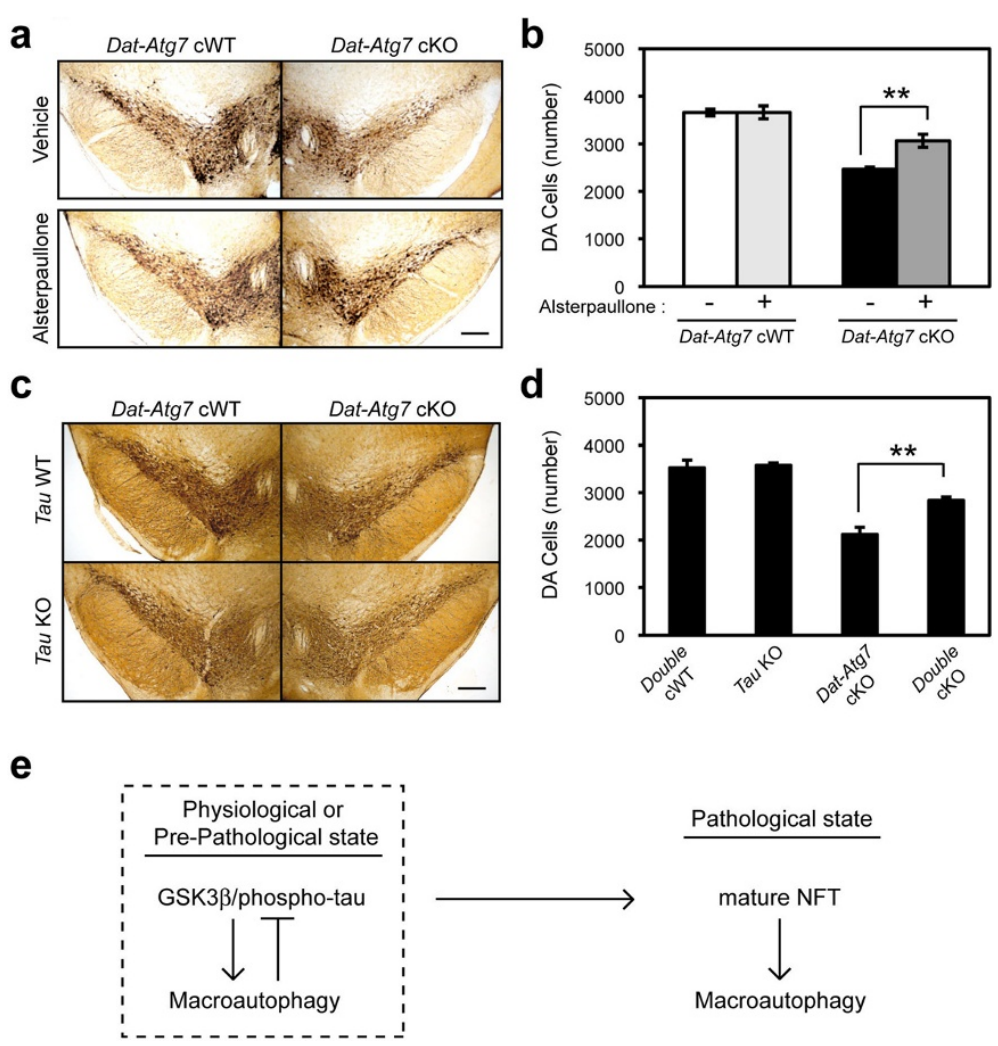

Figure 5 Neuroprotection of Atg7-deficient CNS neurons in vivo. (a-b) Pharmacological rescue of Atg7-deficient midbrain DA neuron loss by systemic injection of the selective GSK3B/CDK5 inhibitor Alsterpaullone. Five-week-old mice were dosed daily with $5 \mathrm{mg} / \mathrm{kg}$ Alsterpaullone by intraperitoneal injection for a 3-week period prior to analysis. TH-positive DA neuron loss was suppressed in Alsterpaullone-treated Dat-Atg7 cKO mice, whereas Alsterpaullone-treated control Dat-Atg7 cWT mice were unaffected. $\mathbf{b}$, Quantification of TH-positive DA neuron number.

**, $P<0.01 . n=5-6$ / group. (c-d) Genetic rescue of DA neuron death in Atg7-deficient mice by secondary tau deletion. Immunostaining for TH-positive DA neurons at 3-month of age revealed significant protection of midbrain DA neurons from neurodegeneration in Atg7 single $\mathrm{KO}$ mice (Dat-Atg7 CKO) relative to controls (Dat-Atg7/tau double CWT). $\mathbf{d}$, Quantification of TH-positive DA neuron number. ${ }^{* *}, \mathrm{P}<0.01$.

$\mathrm{n}=4$ - 6 / group. (e) Proposed model of phospho-tau and GSK3 $\beta$ regulation by macroautophagy. In physiological or pre-pathological states, basal macroautophagy regulates endogenous levels of phospho-tau and GSK3 $\beta$ (dashed square). In pathological states or with aging, macroautophagy is impeded, and phospho-tau and GSK3 $\beta$ are accumulated. These in turn lead to feedback induction of the macroautophagy pathway,

although such feedback is ineffective in late-stage disease or in knockout mice.

differentially affected by macroautophagy deficiency. Purkinje neurons deficient in Atg7 display axonal swellings and are rapidly lost [51]. TH-positive midbrain DA neurons display axonal dystrophy and degeneration, ubiquitin/p62-positive inclusions, and delayed cell loss and locomotor dysfunction [52]. Although tau pathology was not investigated in these other models, staining for the Parkinson's disease associated proteins $\alpha$-synuclein and leucine rich repeat kinase-2 (LRRK2) was reported in Atg7-deficient DA neurons [52]. We failed to detect evidence of $\alpha$-synuclein accumulation in our analysis of either midbrain DA neuron-selective or forebrain neuron-selective Atg7-deficient mice detailed above (data not shown). Such discrepancies may reflect differences in the selectivity or timing of the CRE-mediated deletion strains used in the different studies, or selective sensitivity to macroautophagy loss across distinct neuron types. We note that phospho-tau pathology was apparent in the context of either midbrain DA neuronselective or forebrain neuron-selective Atg7-deficiency.

The molecular basis of GSK3 $\beta$ and phospho-tau accumulation in Atg7-deficient neurons remains to be elucidated. We cannot exclude the possibility that GSK3 $\beta$ accumulation is a secondary effect of phospho-tau accumulation. A recent study described intracellular redistribution of GSK3 $\beta$ to multivesicular bodies, albeit in the context of Wnt pathway modulation [53]. As multivesicular bodies directly associate with the macroautophagy machinery, it is possible that GSK3 $\beta$ degradation is selectively modified with macroautophagy loss [54]. Although GSK3 $\beta$ is a strong candidate for the relevant upstream kinase, we hypothesize the involvement of other kinase pathways, particularly given the multiple targets of the pharmacological kinase inhibitor used, Alsterpaullone. Furthermore, Alsterpaullonemediated protection may be mediated through targets in addition to tau, which would be of further interest. 
We propose a role for basal macroautophagy in regulating the metabolism of phospho-tau proteins at physiological or pre-pathological state (Figure 5e). In the context of macroautophagy loss, GSK3 $\beta$ and phosphotau are accumulated, reminiscent of early pathology that precedes human tauopathy. It is interesting to note that both GSK3 $\beta$ and tau are believed to be potent upstream regulators of macroautophagy [55-58]. We hypothesize that this may reflect a feedback loop, where defective macroautophagy leads progressively to more accumulation of phospho-tau and GSK3 $\beta$, and in turn the accumulated phospho-tau and GSK3 $\beta$ both induce macroautophagy activity. Initially such feedback may be effective, although the accumulated proteins form inclusions. But once macroautophagy deficiency is complete, as in late-stage disease or in knockout mice, this feedback would be ineffective. Thus, such a feedback circuit may be an important pathway to rejuvenate the macroautophagy pathway, which is known to wane with aging [59].

\section{Conclusions}

Atg7 cKO in mouse forebrain neurons led to an agedependent neurodegeneration with ubiquitin/p62-positive and phospho-tau/GSK3 $\beta$ inclusions, but not the full pathological features of NFTs in tauopathy. Pharmacological or genetic inhibition of tau phosphorylation in vivo successfully rescued neurodegeneration in the context of macroautophagy-deficiency. As GSK3 $\beta$ and tau are also upstream inducers of macroautophagy, this implicates a negative feedback loop in human pathology.

\section{Methods}

\section{Animal}

CamK-Cre transgenic mice, Dat ${ }^{\text {Cre/+ }}$ mice, Atg $7^{\text {flox/flox }}$ mice, hAPP-Tg and tau KO mice, used in this study were generated previously [19,20,37,60-62]. CamK-Cre $\mathrm{Tg}$ and tau KO mice were purchased from Jackson Laboratories. All animals were maintained in the animal facility of the Columbia University Medical Center. Experimental protocols were approved by the Institutional Animal Care and Use Committee. Genomic DNA extracted from mouse tails was amplified by PCR for genotyping using standard methods. The PCR primers are the followings: 5'-AGA TGT TCG CGA TTA TC-3', 5'-AGC TAC ACC AGA GAC GG-3' for Cre transgene; 5'-TGC TCT GTG AAC TGC CCT GTT T-3', 5'-TGT TCC TGT GCA CTG CCT CAT T-3' for Atg7 wild-type allele; 5'-CTT GGG TGG AGA GGC TAT TC-3', 5'AGG TGA GAT GAC AGG AGA TC-3' for Atg7 floxed allele.

\section{Histology}

Mice were perfused and fixed in 4\% paraformaldehyde and post-fixed at $4^{\circ} \mathrm{C}$ overnight, $50 \mu \mathrm{m}$ coronal brain sections were generated using a vibratome. The sections were blocked with PBS containing 5\% normal donkey serum [NDS], $0.2 \%$ Triton X-100 [Tx] for $1 \mathrm{~h}$, and incubated with the solution (PBS, 1\% NDS, $0.2 \% \mathrm{Tx}$ ) containing primary antibody at $4{ }^{\circ} \mathrm{C}$ overnight. The following antibodies were used; anti-TH (P60101, Pel-Freez), antiTuJ1 (MMS-435P, COVANCE), anti-MAP2 (AB5622, Millipore), anti-cleaved caspase-3 [Asp175] (\#9661, Millipore), anti-active caspase-3 (AB3623, Cell Signaling Technology), anti-ubiquitin (Sigma-Aldrich), anti-p62 (03-GP62-C, American Research Products), anti-A $\beta$ [4G8] (SIG39200, COVANCE), anti-A $\beta$ [6E10] (SIG39300, COVANCE), anti- $\alpha$ Synuclein (610786, BD Bioscience) (AB5038, Millipore) (ab1903, ab24715, Abcam), anti-phosph-tau TG3 and PHF1 (gifts from Dr. Peter Davies, Alberts Einstein College of Medicine), anti-phospho-tau AT8, AT100, AT180, and AT270 (Pierce), anti-total GSK3 $\beta$ (\#9315, Cell Signaling Technology), anti-phospho-GSK3 $\alpha / \beta$ [Y279/Y216] (ab52188, Abcam), anti-phospho-GSK3 $\beta$ [S9] (ab30619, Abcam), anti-total CRMP2 (\#9393, Cell Signaling Technology), anti-phospho-CRMP2 [T514] (\#9397, Cell Signaling Technology), anti-Cdk5 (MAB5410, Millipore), anti-p35/ 25 (\#2680, Cell Signaling Technology), anti- $\beta$-catenin (\#9581, 9587, Cell Signaling Technology), and anti$\beta$-catenin (\#610154, BD Biosciecnes). For secondary detection, Cy3- or FITC-conjugated antibodies were incubated for $1 \mathrm{~h}$ (Jackson ImmunoResearch). Photographs were taken using a Zeiss LSM 510 Meta confocal microscope.

\section{Neuron counting}

To obtain neuronal cell count, $50 \mu \mathrm{m}$ coronal brain sections were made using a vibratome. In order to count CA1 neurons, the first 30 sections from the rostral hippocampus were stained with rabbit anti-MAP2 antibody (AB5622, Millipore) at a dilution of 1:500, as well as NeuroTrace ${ }^{\mathrm{TM}}$ Fluorescent Nissl stain (N21480, Invitrogen). MAP2-positive neurons were visualized using a Cy3-conjugated secondary antibody (Jackson ImmunoResearch). MAP2 and Nissl double-positive neurons in the CA1 regions were counted manually. In order to count TH-positive neurons, sections covering the entire substantia nigra (25-30 sections / mouse) were stained with sheep anti-TH antibody (P60101, Pel-Freez) at a dilution of 1:250. TH-positive neurons were visualized using the ABC Kit (PK6106, Vector Laboratories) and DAB (SK4100, Vector Laboratories). TH-positive neurons in the substantia nigral regions were counted manually under the light microscope.

\section{Electron microscopy}

Electron microscopic analysis was as described [61]. Anesthetized mice were perfused and fixed in PBS 
containing $4 \%$ paraformaldehyde and $0.5 \%$ gultaralaldehyde. The brains were post-fixed at $4^{\circ} \mathrm{C}$ for $2 \mathrm{~h}$, and the $80 \mu \mathrm{m}$ vibratome sections were made. The sections were treated in $1 \%$ osmium tetroxide, then dehydrated in pure ethanol and infiltrated overnight with Epon 812. Epon was polymerized at $60^{\circ} \mathrm{C}$ for $24 \mathrm{~h}$, cooled and embedded in a larger Epon capsule. Ultrathin sections were cut with an MT5000 ultramicrotome, stained with uranyl acetate and lead citrate. Images were taken with a JOEL 100S Electron Microscope (JOEL USA).

\section{Tissue fractionation}

Preparation of soluble and insoluble fractions was performed as described with some modifications [14]. Cortical and hippocampal tissues from mouse brains were homogenized in $5 \times$ volume of ice-cold $0.25 \mathrm{M}$ sucrose buffer $(50 \mathrm{mM}$ Tris- $\mathrm{HCl}$ [pH7.6]) containing protease inhibitors (P8340, Sigma) and phosphatase inhibitors (\#78420, Thermo Scientific). The homogenized tissues were centrifuged at $500 \times \mathrm{g}$ for $10 \mathrm{~min}$ at $4^{\circ} \mathrm{C}$. The supernatants were lysed with an equal volume of cold sucrose buffer containing $1 \%$ Triton X-100. The lysates were centrifuged at $13,000 \times \mathrm{g}$ for $15 \mathrm{~min}$ at $4^{\circ} \mathrm{C}$. The supernatants contained the soluble fraction. The pellets were resuspended in 1\% SDS in PBS (insoluble fraction). Both fractions were subjected to standard Western Blotting analysis. The antibodies used here are: anti-phospho-tau AT8, AT100, AT180, AT270, TG3 and PHF1, anti-Tau1 and anti-Actin (ab3280, Abcam). Horseradish peroxidaseconjugated secondary antibodies (Jackson ImmunoResearch) and SuperSignal West Pico or Dura (\#34077, 34075, Pierce) were used for detection.

\section{Electrophysiology}

Brains from CamK-Atg7 cWT and cKO mice littermates ( $\sim 12$ weeks of age) were quickly removed and transverse hippocampal slices $(400 \mu \mathrm{m})$ were isolated with a Leica VT1200 Vibratome (Leica, Bannockburn, IL), and placed in ice-cold cutting solution (CS: $110 \mathrm{mM}$ Sucrose, 60 $\mathrm{mM} \mathrm{NaCl}, 3 \mathrm{mM} \mathrm{KCl}, 1.25 \mathrm{mM} \mathrm{NaH} \mathrm{PO}_{4}, 28 \mathrm{mM}$ $\mathrm{NaHCO}_{3}, 0.5 \mathrm{mM} \mathrm{CaCl}, 7 \mathrm{mM} \mathrm{MgCl}, 5 \mathrm{mM}$ Glucose, $0.6 \mathrm{mM}$ Ascorbate. Slices were placed in an interface chamber (Scientific Systems Design, Mississauga, Ontario, Canada) and maintained at $32^{\circ} \mathrm{C}$ in ACSF (2 $\mathrm{ml} / \mathrm{min}$ ) containing $125 \mathrm{mM} \mathrm{NaCl}, 2.5 \mathrm{mM} \mathrm{KCl}, 1.25$ $\mathrm{mM} \mathrm{NaH} \mathrm{PO}_{4}, 25 \mathrm{mM} \mathrm{NaHCO}, 25 \mathrm{mM}$ D-glucose, 2 $\mathrm{mM} \mathrm{CaCl} 2$, and $1 \mathrm{mM} \mathrm{MgCl}$. All solutions were constantly caboxygenated with $95 \% \mathrm{O}_{2}+5 \% \mathrm{CO}_{2}$. Slices were allowed to recover for $120 \mathrm{~min}$ on the electrophysiology rig prior to experimentation. Bipolar stimulating electrodes (92:8 Pt:Y) were placed at the border of area CA3 and area CA1 along the Schaffer-Collateral pathway. ACSF-filled glass recording electrodes (1-3 M 2 ) were placed in stratum radiatum of area CA1. Basal synaptic transmission was assessed for each slice by applying gradually increasing stimuli $(0.5-15 \mathrm{~V})$, using a stimulus isolator (A-M Systems, Carlsborg, WA) and determining the input:output relationship. All subsequent stimuli applied to slices was equivalent to the level necessary to evoke a fEPSP that was $\sim 40 \%$ of the maximal initial slope that could be evoked. Synaptic efficacy was continuously monitored $(0.05 \mathrm{~Hz})$. Sweeps were averaged together every $2 \mathrm{~min}$. fEPSPs were amplified (A-M Systems Model 1800) and digitized (Digidata 1440, Molecular Devices, Sunnyvale, CA) prior to analysis (pClamp, Molecular Devices, Sunnyvale, CA). Stable baseline synaptic transmission was established for 30 min. Slices were given high-frequency stimulation (HFS) to induce long-term potentiation (LTP) using one train of $100 \mathrm{~Hz}$ for one second. Stimulus intensity of the HFS was matched to the intensity used in the baseline recordings. fEPSP initial slopes from averaged traces were normalized to those recorded during baseline. Two-way RM-ANOVA were used for electrophysiological data analysis with $\mathrm{p}<0.05$ as significance criteria.

\section{Fear conditioning}

10-13-mon-old male CamK-Atg7 cWT or CamK-Atg7 cKO mice were used $(\mathrm{n}=8-10)$. The mice were placed in a conditioning chamber (Med Associates) for $2 \mathrm{~min}$ before the onset of a tone (conditioned stimulus) (30 s, $85 \mathrm{~dB}$ sound at $2800 \mathrm{~Hz}$ ) and conditioned by a single electrical foot shock $(0.45 \mathrm{~mA})$ in the last $2 \mathrm{~s}$. The mice were left in the chamber for another $30 \mathrm{~s}$ and placed back into their home cage. Contextual fear learning was measured in the same chamber $24 \mathrm{~h}$ after the training by monitoring the freezing for $5 \mathrm{~min}$ without electrical shock. Cued fear learning was measured $24 \mathrm{~h}$ after the contextual testing. The mice were placed in a novel chamber for $2 \mathrm{~min}$ (pre-conditioning). After that, the mice were exposed to the conditioned stimulus for 3 min, and the freezing was monitored. Freezing behavior was scored using FreezeView software (Med Associates Inc.).

\section{Drug injection}

Five-week-old Dat-Atg7 cWT and Dat-Atg7 cKO mice were treated with Alsterpaullone (A1136, A.G. Scientific) [35]. The drug was dissolved in saline containing $20 \%$ DMSO/ 25\% Tween80, sonicated, and injected intraperitoneally at a dose of $5 \mathrm{mg} / \mathrm{kg}$ every day for 3 weeks. After the final injection, the mice were perfused and processed for histological analyses. We used Dat-Atg7 cWT mice as controls for Dat-Atg7 cKO mice, to address potential phenotypes due to Cre transgene inserted at the DAT locus [62]. 


\section{Statistical analysis}

All comparisons between groups were made using the Mann-Whitney U-test (for two samples) or nonrepeated measures ANOVA (for multiple samples). The values are expressed as the means \pm S.E. A $p$ value less than 0.05 is considered significant.

\section{Additional files}

Additional file 1: Intracellular ubiquitin and p62 positive inclusions in 6-month-old CamK-Atg7 cKO mice. Ubiquitin-positive inclusions are almost completely overlapped with p62-positive inclusions in the cerebral cortex of CamK-Atg7 cKO mice. Ubiquitin/p62-positive inclusions were already seen at 2-month-old Atg7 CKO mice. Bar, $10 \mu \mathrm{m}$.

\section{Additional file 2: Progressive neurodegeneration in midbrain DA} neuron-specific Atg7-deficient (Dat-Atg7 cKO) mice. (a-b) Progressive loss of DA neurons in Dat-Atg7 CKO mice. a, Representative midbrain sections stained with polyclonal antibody specific for TH.Bar, $250 \mu \mathrm{m}$. b, Quantification of TH-positive DA neuron number as in (a). White bars, Dat-Atg7 CWT. Black bars, Dat-Atg7 cKO. $n=3-7$ for each group. **, $\mathrm{P}<0.01$. (c-d) Cytoplasmic and dendritic inclusions in Dat-Atg7 CKO mice. Ubiquitin-positive ( $c$, red) and p62/SQSTM1-positive ( $d$, red) inclusions were present in TH-positive DA neurons (green) of 1-month-old Dat-Atg7 cKO mice, but were never seen in control Dat-Atg7 CWT mice. Bars, 10 $\mu \mathrm{m}$. (e) Phospho-tau-positive inclusions in TH-positive DA neurons in DatAtg7 CKO mice. Phospho-tau specific antibodies (red), AT8, AT100, and TG3, stained inclusions (arrows) in the soma and dendrites of $\mathrm{TH}$-positive DA neurons (green) in Dat-Atg7 cKO mice. AT8, tau phosphorylated at Ser202/Thr205. AT100, tau phosphorylated at Ser212/Thr214. TG3, tau phosphorylated at Thr231/Ser235. Bar, $10 \mu \mathrm{m}$. (f) GSK3ß-positive inclusions in TH-positive DA neurons in Dat-Atg7 cKO mice. Antibodies recognizing total, activated form (Tyr279/Tyr216), and inactivated form (Ser9) of GSK3 $\beta$ (red), stained the inclusions (arrows) in TH-positive DA neurons (green) in Dat-Atg7 CKO mice. Bar, $10 \mu \mathrm{m}$.

Additional file 3: APP/A $\beta$-negative, a-Synuclein-negative, and Thioflavin S-negative inclusions in CamK-Atg7 cKO mice. (a) The ubiquitin-positive inclusions (green) in 1-year-old CamK-Atg7 cKO mice did not contain mouse $A \beta$ (red) (left). 4G8, monoclonal antibody to amino acid residues 17-24 of $A \beta$, was used. Ten-month-old transgenic mice bearing a mutant form of human APP (K670N/M671L/N717F, J20 line) were used as positive control for $A \beta$ plaque staining (right). Similar negative results were obtained by $6 \mathrm{E} 10$, another antibody to amino acid residues 1-16 of $A \beta$ (data not shown). Bars, $10 \mu \mathrm{m}$. (b) The ubiquitinpositive inclusions (green) in 1-year-old CamK-Atg7 cKO mice did not contain mouse a-Synuclein (red). Four different anti-a-synuclein antibodies were used for the double staining. None of four anti-asynuclein antibodies could detect any positive signals (red) in ubiquitinpositive inclusions (green). Bar, $10 \mu \mathrm{m}$. (c) Ubiquitin-positive inclusions (red) in 1-year-old CamK-Atg7 CKO mice were negative for Thioflavin S staining (green, left). Thioflavin $\mathrm{S}$ stains plaques from $\beta$-amyloid and neurofibrillary tangles. Ten-month-old J20 APP transgenic mice were used as positive control for Thioflavin S staining (right). Bars, $20 \mu \mathrm{m}$.

Additional file 4: Immunohistochemical analyses of Atg7-deficient neurons. (a-b) CRMP2-positive inclusions in cortical neurons in CamKAtg7 CKO mice. a, An antibody recognizing total CRMP2 (red), stained p62-positive inclusions (green) in cortical neurons of CamK-Atg7 cKO mice. Bar, $10 \mu \mathrm{m}$. b, An antibody recognizing phosphorylated forms of CRMP2 at Thr514 residues (red), stained p62-positive inclusions (green) in cortical neurons of CamK-Atg7 CKO mice. Bar, $10 \mu \mathrm{m}$. (c) $\beta$-Cateninnegative inclusions in TH-positive DA neurons in Dat-Atg7 cKO mice. Antibodies recognizing $\beta$-Catenin (red) did not stain the inclusions in $\mathrm{TH}$ positive DA neurons (green) in Dat-Atg7 cKO mice. Bar, $10 \mu \mathrm{m}$. (d) CDK5negative inclusions in TH-positive DA neurons in Dat-Atg7 CKO mice. Antibodies recognizing CDK5 (red) did not stain the inclusions in $\mathrm{TH}$ positive DA neurons (green) in Dat-Atg7 cKO mice. Bar, $10 \mu \mathrm{m}$.
Additional file 5: Neuroprotection of Atg7-deficient CNS neurons in vivo. (a) Alsterpaullone can reduce phospho-tau accumulation in the context of macroautophagy inhibition. N2a cells were treated with $1 \mu \mathrm{M}$ Alsterpaullone in the context of $100 \mu \mathrm{M}$ chloroquine treatment for $24 \mathrm{~h}$. Cells were lysed in RIPA buffer and subjected to standard Western blotting analysis. Phospho-tau levels were detected by AT8 antibody. (b-c) Ubiquitin-positive inclusion formation was unaffected by systemic injection of Alsterpaullone in the context of Dat-Atg7 CKO mice. Bar, 10 $\mu \mathrm{m}$. C, Quantification of ubiquitin-positive inclusion number per THneuron in Dat-Atg7 cKO mice. No inclusions were observed in Dat-Atg7 cWT mice. $n>60$ neurons per genotype. (d-e) Ubiquitin-positive inclusion formation (red) was not changed in TH-positive DA neurons (green) of Dat-Atg7/tau double CKO mice relative to Dat-Atg7 CKO mice. No ubiquitin-positive inclusions were detected in tau KO mice. Bar, 10 $\mu \mathrm{m}$. e, Quantification of ubiquitin-positive inclusion number per THneuron in Dat-Atg7/tau double cKO mice. $n>60$ neurons per genotype.

\section{Competing interests}

The authors declare no competing interests.

\section{Authors' contributions}

$\mathrm{KI}, \mathrm{JR}, \mathrm{HK}, \mathrm{EC}, \mathrm{JK}$, and MK performed the experiments. KI, HK, EK, EC, and AA analyzed the results. $\mathrm{KI}$ and $\mathrm{AA}$ designed the study and wrote the manuscript. All authors read and approved the final manuscript.

\section{Acknowledgements}

We would like to thank G. Di Paulo, and O. Hobert for suggestions and comments on the manuscript, R. Hen for generously providing Dat ${ }^{\mathrm{Cre} /+}$ mice, P. Davies for generously providing phospho-tau antibodies, E. Kominami, T. Chiba, and K. Tanaka for generously providing Atg $7^{\text {flox/flox }}$ mice, J.Q. Trojanowski and D. Dickson for electron microscopic analysis, and T. Iwasato, J. Dunning, C. Doege, H. Rhinn, D. MacLeod, W. Vanti, S. Vasishta for technical help. This work was supported by grants from Kanae Foundation for the Promotion of Medical Science, and Research Foundation ITSUU Laboratory to K.I. K.I. was a postdoctoral fellow of New York Stem Cell Foundation. This work was supported by grants from the Michael J. Fox Foundation, NINDS, and NIA to A.A.

\section{Author details}

${ }^{1}$ Departments of Pathology and Neurology, Taub Institute, Columbia University Medical Center, 650 W. 168th St., New York, NY 10032, USA ${ }^{2}$ Center for Neural Science, New York University, 4 Washington Place, New York, NY 10003, USA. ${ }^{3}$ Department of Pharmacological Sciences and Stony Brook University Proteomics Center, Stony Brook University, Stony Brook, NY 11794, USA. ${ }^{4}$ Protein Metabolism Project, Tokyo Metropolitan Institute of Medical Science, Kamikitazawa 2-1-6, Setagaya-ku, Tokyo 156-8506, Japan.

Received: 22 May 2012 Accepted: 5 September 2012 Published: 21 September 2012

\section{References}

1. Abeliovich A, Flint Beal M: Parkinsonism genes: culprits and clues. J Neurochem 2006, 99:1062-1072.

2. Ross CA, Poirier MA: Protein aggregation and neurodegenerative disease. Nat Med 2004, 10:(Suppl)S10-S17.

3. Selkoe DJ: Cell biology of protein misfolding: the examples of Alzheimer's and Parkinson's diseases. Nat Cell Biol 2004, 6:1054-1061.

4. Petrucelli L, Dawson TM: Mechanism of neurodegenerative disease: role of the ubiquitin proteasome system. Ann Med 2004, 36:315-320.

5. Nixon RA: Autophagy in neurodegenerative disease: friend, foe or turncoat? Trends Neurosci 2006, 29:528-535.

6. Anglade P, Vyas S, Javoy-Agid F, Herrero MT, Michel PP, Marquez J, MouattPrigent A, Ruberg M, Hirsch EC, Agid Y: Apoptosis and autophagy in nigral neurons of patients with Parkinson's disease. Histol Histopathol 1997. 12:25-31.

7. Reggiori F, Klionsky DJ: Autophagy in the eukaryotic cell. Eukaryot Cell 2002, 1:11-21.

8. Klionsky DJ, Ohsumi Y: Vacuolar import of proteins and organelles from the cytoplasm. Annu Rev Cell Dev Biol 1999, 15:1-32. 
9. Cuervo AM, Wong ES, Martinez-Vicente M: Protein degradation, aggregation, and misfolding. Mov Disord 2010, 25:(Suppl 1)S49-S54.

10. Boland B, Kumar A, Lee S, Platt FM, Wegiel J, Yu WH, Nixon RA: Autophagy induction and autophagosome clearance in neurons: relationship to autophagic pathology in Alzheimer's disease. J Neurosci 2008, 28:6926-6937.

11. Eblan MJ, Walker JM, Sidransky E: The glucocerebrosidase gene and Parkinson's disease in Ashkenazi Jews. N Engl J Med 2005, 352:728-731. author reply 728-731.

12. Ramirez A, Heimbach A, Grundemann J, Stiller B, Hampshire D, Cid LP, Goebel I, Mubaidin AF, Wriekat AL, Roeper J, et al: Hereditary parkinsonism with dementia is caused by mutations in ATP13A2, encoding a lysosomal type 5 P-type ATPase. Nat Genet 2006, 38:1184-1191.

13. Komatsu M, Waguri S, Chiba T, Murata S, Iwata J, Tanida I, Ueno T, Koike M, Uchiyama Y, Kominami E, Tanaka K: Loss of autophagy in the central nervous system causes neurodegeneration in mice. Nature 2006, 441:880-884.

14. Hara T, Nakamura K, Matsui M, Yamamoto A, Nakahara Y, Suzuki-Migishima R, Yokoyama M, Mishima K, Saito I, Okano H, Mizushima N: Suppression of basal autophagy in neural cells causes neurodegenerative disease in mice. Nature 2006, 441:885-889.

15. Nishiyama J, Miura E, Mizushima N, Watanabe M, Yuzaki M: Aberrant membranes and double-membrane structures accumulate in the axons of Atg5-null Purkinje cells before neuronal death. Autophagy 2007, 3:591-596.

16. Levine B, Kroemer G: Autophagy in the pathogenesis of disease. Cell 2008, 132:27-42.

17. Komatsu M, Waguri S, Koike M, Sou YS, Ueno T, Hara T, Mizushima N, Iwata J, Ezaki J, Murata S, et al: Homeostatic levels of p62 control cytoplasmic inclusion body formation in autophagy-deficient mice. Cell 2007, 131:1149-1163.

18. Klionsky DJ: Neurodegeneration: good riddance to bad rubbish. Nature 2006, 441:819-820.

19. Komatsu M, Waguri S, Ueno T, Iwata J, Murata S, Tanida I, Ezaki J, Mizushima N, Ohsumi Y, Uchiyama Y, et al: Impairment of starvation-induced and constitutive autophagy in Atg7-deficient mice. J Cell Biol 2005, 169:425-434.

20. Tsien JZ, Chen DF, Gerber D, Tom C, Mercer EH, Anderson DJ, Mayford M, Kandel ER, Tonegawa S: Subregion- and cell type-restricted gene knockout in mouse brain. Cell 1996, 87:1317-1326.

21. Pankiv S, Clausen TH, Lamark T, Brech A, Bruun JA, Outzen H, Overvatn A, Bjorkoy G, Johansen T: p62/SQSTM1 binds directly to Atg8/LC3 to facilitate degradation of ubiquitinated protein aggregates by autophagy. J Biol Chem 2007, 282:24131-24145.

22. Yu WH, Kumar A, Peterhoff C, Shapiro Kulnane L, Uchiyama Y, Lamb BT, Cuervo AM, Nixon RA: Autophagic vacuoles are enriched in amyloid precursor protein-secretase activities: implications for beta-amyloid peptide over-production and localization in Alzheimer's disease. Int J Biochem Cell Biol 2004, 36:2531-2540.

23. Wang Y, Martinez-Vicente M, Kruger U, Kaushik S, Wong E, Mandelkow EM, Cuervo AM, Mandelkow E: Tau fragmentation, aggregation and clearance: the dual role of lysosomal processing. Hum Mol Genet 2009, 18:4153-4170

24. Hamano T, Gendron TF, Causevic E, Yen SH, Lin WL, Isidoro C, Deture M, Ko LW: Autophagic-lysosomal perturbation enhances tau aggregation in transfectants with induced wild-type tau expression. Eur J Neurosci 2008, 27:1119-1130.

25. Sarkar S, Rubinsztein DC: Huntington's disease: degradation of mutant huntingtin by autophagy. FEBS J 2008, 275:4263-4270.

26. Qin ZH, Wang Y, Kegel KB, Kazantsev A, Apostol BL, Thompson LM, Yoder J, Aronin N, DiFiglia M: Autophagy regulates the processing of amino terminal huntingtin fragments. Hum Mol Genet 2003, 12:3231-3244.

27. Wang $X$, Fan H, Ying Z, Li B, Wang H, Wang G: Degradation of TDP-43 and its pathogenic form by autophagy and the ubiquitin-proteasome system. Neurosci Lett 2010, 469:112-116.

28. Urushitani M, Sato T, Bamba H, Hisa Y, Tooyama I: Synergistic effect between proteasome and autophagosome in the clearance of polyubiquitinated TDP-43. J Neurosci Res 2010, 88:784-797.

29. Webb JL, Ravikumar B, Atkins J, Skepper JN, Rubinsztein DC: AlphaSynuclein is degraded by both autophagy and the proteasome. J Biol Chem 2003, 278:25009-25013.
30. Zhou L, Miller BL, McDaniel CH, Kelly L, Kim OJ, Miller CA: Frontotemporal dementia: neuropil spheroids and presynaptic terminal degeneration. Ann Neurol 1998, 44:99-109.

31. Dickson DW: Neuropathology of Pick's disease. Neurology 2001, 56:S16-S20.

32. Luna-Munoz J, Chavez-Macias L, Garcia-Sierra F, Mena R: Earliest stages of tau conformational changes are related to the appearance of a sequence of specific phospho-dependent tau epitopes in Alzheimer's disease. J Alzheimers Dis 2007, 12:365-375.

33. Mazanetz MP, Fischer PM: Untangling tau hyperphosphorylation in drug design for neurodegenerative diseases. Nat Rev Drug Discov 2007, 6:464-479.

34. Yoshimura T, Kawano Y, Arimura N, Kawabata S, Kikuchi A, Kaibuchi K: GSK3 beta regulates phosphorylation of CRMP-2 and neuronal polarity. Cell 2005, 120:137-149.

35. Selenica ML, Jensen HS, Larsen AK, Pedersen ML, Helboe L, Leist M, Lotharius J: Efficacy of small-molecule glycogen synthase kinase-3 inhibitors in the postnatal rat model of tau hyperphosphorylation. $\mathrm{Br} J$ Pharmacol 2007, 152:959-979.

36. Leost M, Schultz C, Link A, Wu YZ, Biernat J, Mandelkow EM, Bibb JA, Snyder GL, Greengard P, Zaharevitz DW, et al: Paullones are potent inhibitors of glycogen synthase kinase-3beta and cyclin-dependent kinase 5/p25. Eur J Biochem 2000, 267:5983-5994.

37. Dawson HN, Ferreira A, Eyster MV, Ghoshal N, Binder LI, Vitek MP: Inhibition of neuronal maturation in primary hippocampal neurons from tau deficient mice. J Cell Sci 2001, 114:1179-1187.

38. Jimenez-Mateos EM, Gonzalez-Billault C, Dawson HN, Vitek MP, Avila J: Role of MAP1B in axonal retrograde transport of mitochondria. Biochem J 2006, 397:53-59.

39. Ishizawa T, Sahara N, Ishiguro K, Kersh J, McGowan E, Lewis J, Hutton M, Dickson DW, Yen SH: Co-localization of glycogen synthase kinase-3 with neurofibrillary tangles and granulovacuolar degeneration in transgenic mice. Am J Pathol 2003, 163:1057-1067.

40. Ferrer I, Barrachina M, Tolnay M, Rey MJ, Vidal N, Carmona M, Blanco R, Puig B: Phosphorylated protein kinases associated with neuronal and glial tau deposits in argyrophilic grain disease. Brain Pathol 2003, 13:62-78.

41. Ferrer I, Barrachina M, Puig B: Glycogen synthase kinase-3 is associated with neuronal and glial hyperphosphorylated tau deposits in Alzheimer's disease, Pick's disease, progressive supranuclear palsy and corticobasal degeneration. Acta Neuropathol 2002, 104:583-591.

42. Leroy K, Yilmaz Z, Brion JP: Increased level of active GSK-3beta in Alzheimer's disease and accumulation in argyrophilic grains and in neurones at different stages of neurofibrillary degeneration. Neuropathol Appl Neurobiol 2007, 33:43-55.

43. Leroy K, Boutajangout A, Authelet M, Woodgett JR, Anderton BH, Brion JP: The active form of glycogen synthase kinase-3beta is associated with granulovacuolar degeneration in neurons in Alzheimer's disease. Acta Neuropathol 2002, 103:91-99.

44. Brunden KR, Trojanowski JQ, Lee VM: Evidence that non-fibrillar tau causes pathology linked to neurodegeneration and behavioral impairments. J Alzheimers Dis 2008, 14:393-399.

45. Hoozemans JJ, van Haastert ES, Nijholt DA, Rozemuller AJ, Eikelenboom P, Scheper W: The unfolded protein response is activated in pretangle neurons in Alzheimer's disease hippocampus. Am J Pathol 2009, 174:1241-1251.

46. Nixon RA, Wegiel J, Kumar A, Yu WH, Peterhoff C, Cataldo A, Cuervo AM: Extensive involvement of autophagy in Alzheimer disease: an immunoelectron microscopy study. J Neuropathol Exp Neurol 2005, 64:113-122.

47. Sasaki S: Autophagy in spinal cord motor neurons in sporadic amyotrophic lateral sclerosis. J Neuropathol Exp Neurol 2011, 70:349-359.

48. Sun Y, Liou B, Ran H, Skelton MR, Williams MT, Vorhees CV, Kitatani K, Hannun YA, Witte DP, Xu YH, Grabowski GA: Neuronopathic Gaucher disease in the mouse: viable combined selective saposin $C$ deficiency and mutant glucocerebrosidase (V394L) mice with glucosylsphingosine and glucosylceramide accumulation and progressive neurological deficits. Hum Mol Genet 2010, 19:1088-1097.

49. Nagata E, Sawa A, Ross CA, Snyder SH: Autophagosome-like vacuole formation in Huntington's disease lymphoblasts. Neuroreport 2004, 15:1325-1328

50. Nixon RA, Yang DS, Lee JH: Neurodegenerative lysosomal disorders: a continuum from development to late age. Autophagy 2008, 4:590-599. 
51. Komatsu M, Wang QJ, Holstein GR, Friedrich VL Jr, Iwata J, Kominami E, Chait BT, Tanaka K, Yue Z: Essential role for autophagy protein Atg7 in the maintenance of axonal homeostasis and the prevention of axonal degeneration. Proc Natl Acad Sci U S A 2007, 104:14489-14494.

52. Friedman LG, Lachenmayer ML, Wang J, He L, Poulose SM, Komatsu M, Holstein GR, Yue Z: Disrupted autophagy leads to dopaminergic axon and dendrite degeneration and promotes presynaptic accumulation of alpha-synuclein and LRRK2 in the brain. J Neurosci 2012, 32:7585-7593.

53. Taelman VF, Dobrowolski R, Plouhinec JL, Fuentealba LC, Vorwald PP, Gumper I, Sabatini DD, De Robertis EM: Wnt signaling requires sequestration of glycogen synthase kinase 3 inside multivesicular endosomes. Cell 2010, 143:1136-1148.

54. Mizushima N, Levine B, Cuervo AM, Klionsky DJ: Autophagy fights disease through cellular self-digestion. Nature 2008, 451:1069-1075.

55. Lin SY, Li TY, Liu Q, Zhang C, Li X, Chen Y, Zhang SM, Lian G, Ruan K, Wang Z, et al: GSK3-TIP60-ULK1 signaling pathway links growth factor deprivation to autophagy. Science 2012, 336:477-481.

56. Sarkar S, Krishna G, Imarisio S, Saiki S, O'Kane CJ, Rubinsztein DC: A rational mechanism for combination treatment of Huntington's disease using lithium and rapamycin. Hum Mol Genet 2008, 17:170-178.

57. Lin WL, Lewis J, Yen SH, Hutton M, Dickson DW: Ultrastructural neuronal pathology in transgenic mice expressing mutant (P301L) human tau. $J$ Neurocytol 2003, 32:1091-1105.

58. Pacheco CD, Elrick MJ, Lieberman AP: Tau deletion exacerbates the phenotype of Niemann-Pick type $\mathrm{C}$ mice and implicates autophagy in pathogenesis. Hum Mol Genet 2009, 18:956-965.

59. Cuervo AM: Autophagy and aging: keeping that old broom working. Trends Genet 2008, 24:604-612.

60. Mucke L, Masliah E, Yu GQ, Mallory M, Rockenstein EM, Tatsuno G, Hu K, Kholodenko D, Johnson-Wood K, McConlogue L: High-level neuronal expression of abeta 1-42 in wild-type human amyloid protein precursor transgenic mice: synaptotoxicity without plaque formation. J Neurosci 2000, 20:4050-4058.

61. Mizushima N, Yamamoto A, Matsui M, Yoshimori T, Ohsumi Y: In vivo analysis of autophagy in response to nutrient starvation using transgenic mice expressing a fluorescent autophagosome marker. Mol Biol Cell 2004, 15:1101-1111.

62. Zhuang X, Masson J, Gingrich JA, Rayport S, Hen R: Targeted gene expression in dopamine and serotonin neurons of the mouse brain. $J$ Neurosci Methods 2005, 143:27-32.

doi:10.1186/1750-1326-7-48

Cite this article as: Inoue et al:: Macroautophagy deficiency mediates age-dependent neurodegeneration through a phospho-tau pathway. Molecular Neurodegeneration 2012 7:48.

\section{Submit your next manuscript to BioMed Central and take full advantage of:}

- Convenient online submission

- Thorough peer review

- No space constraints or color figure charges

- Immediate publication on acceptance

- Inclusion in PubMed, CAS, Scopus and Google Scholar

- Research which is freely available for redistribution

Submit your manuscript at www.biomedcentral.com/submit
Ciomed Central 